\title{
Mental Health in Times of the COVID-19 Pandemic
}

\section{Current Knowledge and Implications From a European Perspective}

\author{
Janine Wirkner ${ }^{1}$ (D, Hanna Christiansen ${ }^{2}$, Christine Knaevelsrud ${ }^{3}$, Ulrike Lüken ${ }^{4}$, \\ Susanne Wurm ${ }^{5}$, Silvia Schneider ${ }^{6}$, and Eva-Lotta Brakemeier ${ }^{1}$ \\ ${ }^{1}$ Department of Psychology, University of Greifswald, Germany \\ ${ }^{2}$ Department of Psychology, Philipps-University Marburg, Germany \\ ${ }^{3}$ Department of Education and Psychology, Free University Berlin, Germany \\ ${ }^{4}$ Department of Psychology, Humboldt-University Berlin, Germany \\ ${ }^{5}$ Department for Prevention Research and Social Medicine, University Medicine Greifswald, Germany \\ ${ }^{6}$ Department of Clinical Psychology, Child and Adolescent Psychology, Ruhr University Bochum, Germany
}

\begin{abstract}
The COVID-19 pandemic is one of the most serious health and economic crises of the 21 st century. From a psychological point of view, the COVID-19 pandemic and its consequences can be conceptualized as a multidimensional and potentially toxic stressor for mental health in the general population. This selective literature review provides an overview of longitudinal studies published until June 2021 that have investigated the impact of the COVID-19 pandemic on mental health in the European population. Risk and protective factors identified in the studies are summarized. Forty-two studies that met inclusion and search criteria (COVID-19, mental health, longitudinal, and Europe) in PubMed, Psyclnfo, and Web of Science databases indicate differential effects of the pandemic on mental distress, depression, and anxiety, depending on samples and methods used. Age-specific (e.g., young age), social (e.g., female, ethnical minority, loneliness), as well as physical and mental health-related factors (e.g., pre-pandemic illness) were identified as risk factors for poor mental health. The studies point to several protective factors such as social support, higher cognitive ability, resilience, and self-efficacy. Increasing evidence supports the assumption of the pandemic being a multidimensional stressor on mental health, with some populations appearing more vulnerable than others, although inconsistencies arise. Whether the pandemic will lead to an increase in the prevalence of mental disorders is an open question. Further high-quality longitudinal and multi-national studies and meta-analyses are needed to draw the complete picture of the consequences of the pandemic on mental health.
\end{abstract}

Keywords: COVID-19 pandemic, mental health, clinical psychology, psychotherapy, longitudinal research

The COVID-19 pandemic captivated the world in 2020 with increasing numbers of infections and deaths. Actual data can be retrieved from John Hopkins University (https://coronavirus.jhu.edu/map.html). In Europe, cases and deaths vary by country, region, and point in time, but all individuals have to face the same challenge: containing the pandemic.

The European Union (EU) is successively introducing measures (European Commission, 2021), and while awaiting the relief of heard immunity using effective vaccination, each country is trying to contain the virus with varying levels of lockdown restrictions, especially when faced with new and even more contagious variants of the virus. Research from past epidemics suggests that besides the specific physical health risk of infection, the pandemic and the required measures, and even the virus per se might also threaten mental health (Vindegaard \& Benros, 2020). Following epidemics in 2003 (SARS-CoV-1) and 2012 (MERS-CoV), an increase in depression and anxiety disorders, as well as posttraumatic stress disorder, was observed (for review, see Vindegaard \& Benros, 2020). Also, financial and economic losses that result from the present crisis might pose additional threats to mental health (Boyce et al., 2018; Forbes \& Krueger, 2019). For example, following the financial crises in the United States (2007-2009), individuals who experienced at least one major impact on finance, work, or housing showed a higher probability of depression, anxiety, and substance abuse (Forbes \& Krueger, 2019). In 
line, data from the United Kingdom showed lower mental health following the great recession (Katikireddi et al., 2012) and impaired well-being in individuals who were already sick or disabled before the crisis or who experienced unemployment and loss of income during the recession (Boyce et al., 2018).

In the following, we conceptualize the COVID-19 pandemic as a potential multidimensional stressor. Five characteristics of this potential stressor have been recently postulated (Brakemeier et al., 2020; Gruber et al., 2021). First, the pandemic and its related consequences are of global and worldwide character, and termination remains unclear. Second, there are various individual consequences affecting multiple life domains and threatening mental health (e.g., domestic conflict, unemployment, loneliness). Third, individuals might experience subjective feelings of loss of control and helplessness. Fourth, the pandemic has a systemic impact on several domains in society (e.g., economy, trade, entertainment industry). Fifth, access to protective factors (e.g., sports, social events), including psychotherapeutic treatment, has been limited or blocked during the pandemic.

Due to this multidimensional character of the stressor, almost every individual worldwide is affected - at least to some extend - by the pandemic and the associated policies. Therefore, every individual needs to adapt to the ongoing changes implied by the stressor and show a certain amount of mental flexibility. However, it has long been shown that when the intensity and duration of a stressor exceed the individual's (perceived) resources, the individual is at risk for mental health problems (McEwen \& Stellar, 1993). Accordingly, it has been widely demonstrated in the context of vulnerability-stress models that stressful life events and chronic stress, together with preexisting vulnerability factors, lead to the onset of mental disorders such as depression, posttraumatic stress disorder, and anxiety disorders (Hammen et al., 2009; Marin et al., 2011; Smoller, 2016). If the COVID-19 pandemic is understood as a stressor that differently affects each individual, it seems reasonable to examine the pandemic-specific risk factors. In this context, different age groups are likely to face different challenges, taking the varying developmental processes across the lifespan into account (Brakemeier et al., 2020; Gruber et al., 2021). In addition, social life has been widely affected by pandemic-related measures (e.g., physical distancing, school closures). Finally, it is important to consider pre- and intra-pandemic physical and mental disorders as risk factors, since they predispose to further illness (Brakemeier et al., 2020; Gruber et al., 2021). For example, recovered SARS patients, especially females, from the 2003 epidemic reported heightened perceived (psychological) stress levels up to 1 year following recovery (Lee et al., 2007). In contrast, it is also known that protective factors can buffer the association between vulnerabilities and stress with mental disorders. For example, resilient individuals seem to quickly succeed in the necessary adaptation process during the COVID-19 pandemic, e.g., in the family environment (Davidson et al., 2021; Prime et al., 2020). Therefore, this selective review will also examine whether protective factors were identified in the studies and, if so, which ones.

By conceptualizing the COVID-19 pandemic as a potential multidimensional stressor, it seems reasonable to expect a toxic effect on mental health - at least for individuals with specific risk factors and vulnerabilities. As a first step, this assumption will be examined for the European region by means of a selective review. Given the ever-growing number of COVID-19 research papers and the ongoing pandemic, this article does not aim to present a comprehensive systematic review or meta-analysis (Shamseer et al., 2015). Instead, through a selective review, we seek to provide an overview of the current literature on mental health changes due to COVID-19 over time in Europe, highlighting the stressor perspective by identifying risk factors as well as protective factors.

\section{Methods}

A full-text database search in three databases (PubMed, PsycInfo, and Web of Science) was performed on June 7, 2021, including the four keywords COVID-19, mental health, longitudinal, and Europe. All results published up to this date were considered. In addition, studies that were only or mainly published online (Google search) were screened regarding the inclusion and exclusion criteria. Our search yielded 73 publications (see Electronic Supplementary Material, ESM 1, for records retrieved). The inclusion criteria for study selection were: (1) original research, (2) longitudinal data (prospective or retrospective), (3) mental health focus, and (4) European sample. Accordingly, exclusion criteria were: (1) other than original research (e.g., review, metaanalyses, study protocol, commentary), (2) cross-sectional data, (3) no mental health focus, and (4) no participants from Europe included. Table E1 in ESM 1 summarizes the ratings of the inclusion criteria of both independent raters (JW and ELB), and ESM 1, Table E2 the interrater reliability showing a Cohen's Kappa of $\kappa=.87$. Figure 1 depicts the flow chart of the study selection process. After the removal of 6 duplicates and 25 records who did not meet inclusion criteria, a total of 42 publications were included in the selective review, of which 25 studies contained data collected before the first COVID-19 lockdown (see ESM 2). The other 17 studies contained longitudinal data collected during and/or after the first lockdown in Europe (see ESM 3). Studies that mainly compared cross-sectional measures 


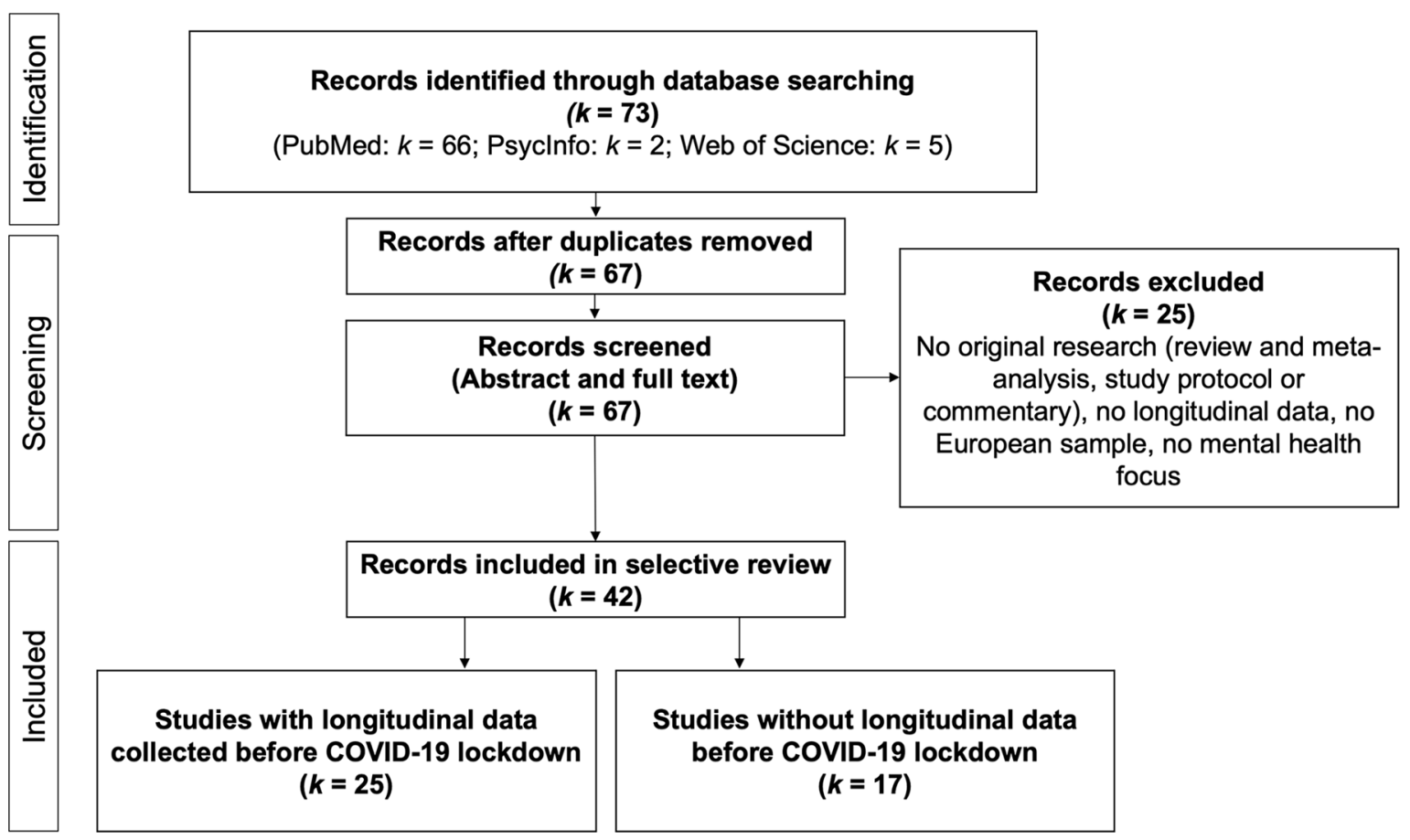

Figure 1. Flow diagram of study selection process.

between time points or were based on identical populations with different outcome measures (e.g., Niedzwiedz et al., 2021; Pierce et al., 2020) were not excluded from this selective review. ESMs 2 and 3 present an overview of the 43 selected studies and study characteristics. The studies included were carefully examined in full text for risk and protective factors for mental health (see ESM 2 and 3).

\section{Results}

\section{The COVID-19 Pandemic and Mental Health in Europe}

Five studies focusing on mental health (mainly anxiety and depression) in the general population were identified, comparing data before the pandemic with data during the pandemic (for a specific description of the studies, see ESM 2). In the UK Household Longitudinal Study, mental distress in April 2020 was higher than in 2018 and 2019 survey waves, and mental health impairments (General Health Questionnaire, GHQ-12) were significantly higher, even when taking longitudinal upward trends into account (Pierce et al., 2020). Further analysis of this study indicated a higher prevalence of psychological distress during lockdown in April 2020 compared to 2017-2019 (30.6\% vs. 19.4\%; Niedzwiedz et al., 2021). In France, during lock- down in April 2020, anxiety symptoms were observed in $20.1 \%$ of the general population, higher than in 20142019 (17.3\%), and participants reported overall decreased mental health (Ramiz et al., 2021). However, depression scores (Patient Health Questionnaire, PHQ-9) remained unchanged (27.6 \% with PHQ-9 score > 4; Ramiz et al., 2021). In Italy, a significant increase in anxiety and depressive symptoms was observed from 2 weeks before the COVID-19 outbreak to April and May 2020 in a sample of 130 participants (Castellini et al., 2021). In contrast, longitudinal data from the Netherlands even showed a small decrease in anxiety and depression (Van der Velden et al., 2021) during the first lockdown in March 2020.

With regard to intra-pandemic comparison data, depression increased during the first lockdown in Spain (March to June 2020), whereas anxiety remained unchanged (González-Sanguino et al., 2021). In England, decreases in anxiety and depression levels were observed from March to August 2020 in the general population (Fancourt et al., 2021). In the UK (PHQ-9; Groarke et al., 2021) and Germany (PHQ-4; Bendau, Plag, et al., 2021), no changes in mental health were observed between March and June 2020. A large sample, including Denmark, France, the Netherlands, and the UK, reported poor mental health outcomes in the beginning of the lockdown in March 2020 (UK showing the highest prevalence of anxiety: 25\%) and a decrease in worries and anxiety until June 2020 (with France showing the slowest relaxation; Varga et al., 2021). 
Table 1. Summary of risk factors for mental health identified in the selected studies of the selective review

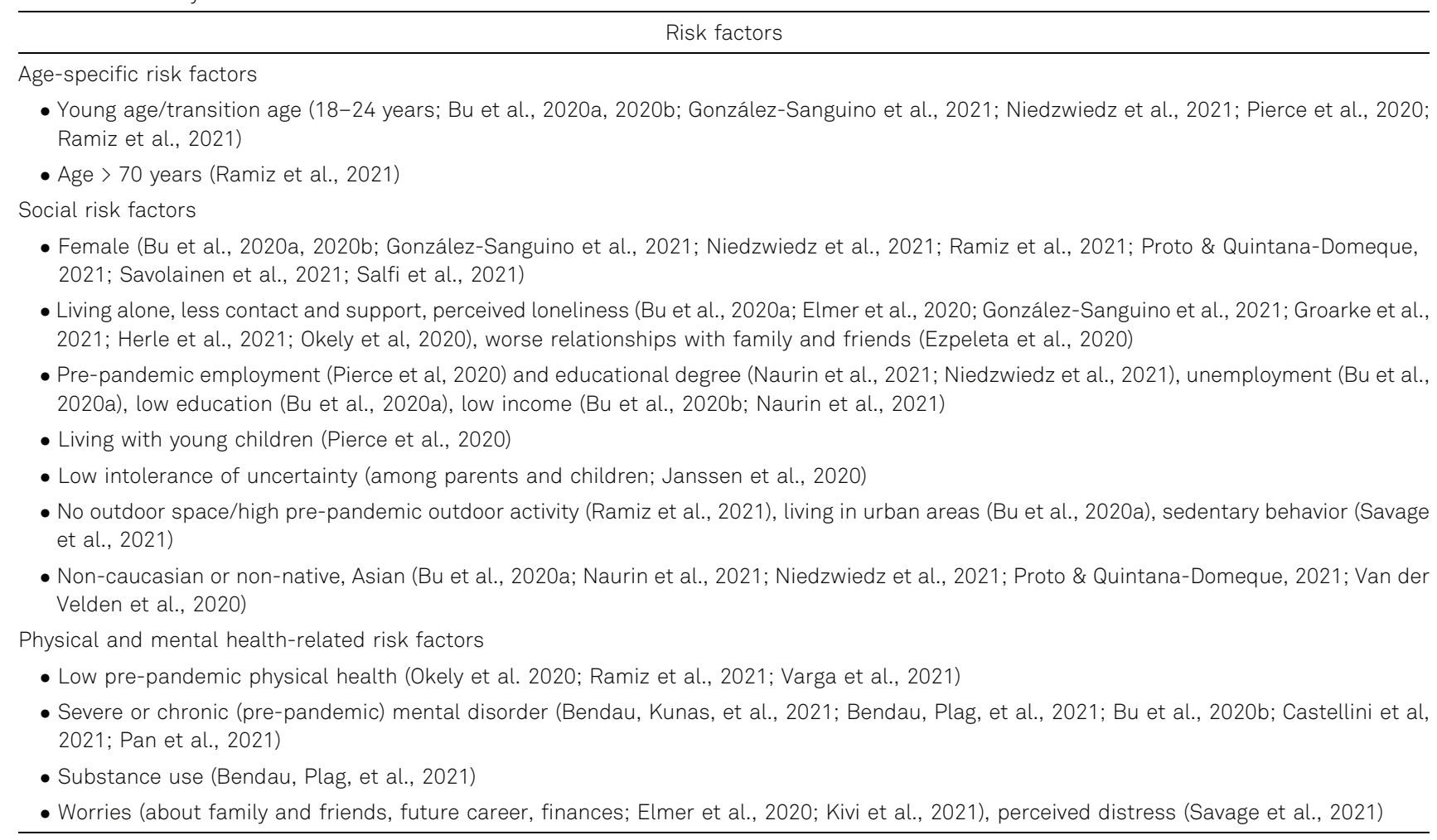

\section{Individuals at Risk}

Eighteen studies out of 42 included studies of the selective review addressed risk factors (42.9\%). Table 1 shows a summary of risk factors identified in the selected studies.

\section{Age-Specific Risk Factors}

A study from Switzerland comparing data from families before the pandemic with data from the first wave indicates that children's well-being $\left(M_{\text {age }}=12.4\right.$ years $)$ and family functioning decreased (Ehrler et al., 2021). In Italian adolescents, an increase in negative affect and a decrease in positive affect were observed (Alivernini et al., 2021). In a study from Spain, mental health problems in children $\left(M_{\text {age }}=13.9\right.$ years $)$ increased during the first lockdown, especially regarding conduct problems, difficulties with peers, but not in hyperactivity-inattention problems (Ezpeleta et al., 2020). Interestingly, in the Netherlands, mentally healthy participants aged 11-17 years did not report changes in depressive symptomatology as measured with the PHQ-9, but their parents did (Janssen et al., 2020).

Comparisons of large representative population-based samples (age $\geq 18$ years) in the UK before and during the pandemic indicated that young age and belonging to the transition age group (16-25 years) were associated with higher psychological distress (Fancourt et al., 2021; Niedzwiedz et al., 2021; Pierce et al., 2020) and loneliness (Bu et al., 2020a). Among the UK university students, mental well-being and physical activity decreased from
October 2019 to October 2020, while sedentary behavior and perceived distress increased (Savage et al., 2021). Similar results were observed in UK psychology students in April and May 2020 (Evans et al., 2021). Other studies indicate that as the pandemic progresses, younger age is a risk factor for depression, anxiety, and loneliness (e.g., $\mathrm{Bu}$ et al., 2020b; Fancourt et al., 2021; González-Sanguino et al., 2021; Varga et al., 2021).

Older adults in the longitudinal Lothian Birth Cohort in Scotland (84 years) indicated lower physical activity but slightly higher experienced social support during the first lockdown (Okely et al., 2020). Also, Swedish older adults (65-71 years) showed comparable health, life satisfaction, and loneliness since 2015 (Kivi et al., 2021). In contrast, longitudinal findings from France in individuals aged 70 years and older indicated a decrease in mental health, reported by $41.5 \%$ during the first lockdown, and an increase in depression and anxiety scores reported in $17.4 \%$ and $14.2 \%$ of the sample, respectively (Ramiz et al., 2021). In Austria, participants aged 60 years and older reported increased loneliness during the first lockdown compared to pre-pandemic, especially those living alone (Stolz et al., 2021).

\section{Social Risk Factors}

Italian health-care workers showed lower sleep quality and more distress during the COVID-19 pandemic (Salfi et al., 2021). Results from other European longitudinal studies indicated that pre-pandemic employment (Pierce et al., 
2020) and a higher educational degree (Naurin et al., 2021; Niedzwiedz et al., 2021) were risk factors for increased mental distress and worry. However, other studies identified unemployment, low education, and low income (Bu et al., 2020a; Fancourt et al., 2021). High education and low income were associated with increased worry among pregnant women (Naurin et al., 2021). Young families were found to experience higher levels of mental distress (Pierce et al., 2020). In families with teenage children, poorer relationships with family and friends and low activity levels were associated with psychological problems (Ezpeleta et al., 2020). High intolerance of uncertainty was also a risk factor (Janssen et al., 2020). Several studies indicated that women were at higher risk for mental health problems than men (e.g., Bendau, Kunas, et al., 2021; Bu et al., 2020a, 2020b; González-Sanguino et al., 2021; Niedzwiedz et al., 2021; Proto \& Quintana-Domeque, 2021; Ramiz et al., 2021; Salfi et al., 2021). The following environmental factors and lower physical activity also appear to contribute to poorer mental health: no outdoor space and high prepandemic outdoor activity (Ramiz et al., 2021), living in urban areas (Bu et al., 2020a), increasing sedentary behavior (Savage et al., 2021). Furthermore, social risk factors include living alone, fewer contacts and support, perceived loneliness (Bu et al., 2020a; Elmer et al., 2020; GonzálezSanguino et al., 2021; Groarke et al., 2021; Herle et al., 2021; Okely et al., 2020), and poorer relationships with family and friends (Ezpeleta et al., 2020).

Loneliness is generally considered a major stressor that is associated with several adverse outcomes (Cacioppo \& Patrick, 2008). Longitudinal data on loneliness in the context of the pandemic from the UK are inconsistent. In a first study, overall loneliness in the general population remained stable between 2015 and 2020 (Niedzwiedz et al., 2021). However, when comparing a 2019 sample from the same study with another cross-sectional sample in March 2020, $\mathrm{Bu}$ et al. observed higher levels of loneliness (18.3\% vs. $8.5 \%$ reported to experience loneliness often; $\mathrm{Bu}$ et al., 2020a).

Finally, longitudinal data indicated non-Caucasian, nonnative (Bu et al., 2020a; Naurin et al., 2021; van der Velden et al., 2020), or Asian (Niedzwiedz et al., 2021) was associated with poorer mental health.

\section{Physical and Mental Health-Related Risk Factors}

Overall, the selected longitudinal data indicated that having a severe or chronic mental disorder (Bendau, Kunas, et al., 2021; Bendau, Plag, et al., 2021; Bu et al., 2020b; Castellini et al., 2021; Pan et al., 2021), substance use (Bendau, Plag, et al., 2021), or low physical health before the pandemic (Okely et al., 2020; Ramiz et al., 2021; Varga et al., 2021) were risk factors for poor mental health during the pandemic. In addition, worries (about family and friends, future career, finances; Elmer et al., 2020; Kivi et al., 2021), and perceived distress (Savage et al., 2021) were associated with lower mental health.

Only one study investigated COVID-19 survivors: Of 797 Spanish COVID-19 survivors, $12.2 \%$ reported mental health problems at 6-month follow-up (Romero-Duarte et al., 2021).

\section{Protective Factors}

Thirteen of the 42 identified studies reported protective factors, which are summarized in Table 2. Resilience (defined here as lower harm avoidant and higher self-directed personality) appeared as a protective factor in a sample of female Italian teachers during the pandemic (as was mindfulness; Matiz et al., 2020). Spiritual well-being was found to be protective in a Spanish population (González-Sanguino et al., 2021).

Having more social support (networks), friends, and living with others have been identified as protective factors in several studies (Bendau, Plag, et al., 2021; Bu et al., 2020b; Elmer et al., 2020; Naurin et al., 2021; Wright et al., 2021). Moreover, longitudinal data showed that higher tolerance of uncertainty seems to support positive affect in teenagers (Janssen et al., 2020).

In the advanced age, general cognitive ability, intellect, and emotional stability might be especially important for well-being and sustained physical activity (Okely et al., 2020). In two further studies, higher education was likewise protective (Herle et al., 2021; Salfi et al., 2021), as was Caucasian ethnicity (Proto \& Quintana-Domeque, 2021). Living in a rural environment was a protective factor, at least in UK citizens (Bu et al., 2020a). Finally, self-efficacy and good knowledge about COVID-19 and treatment options were associated with lower COVID-19 anxiety (Bendau, Plag, et al., 2021).

\section{Discussion}

It is well-known that crises such as the COVID-19 pandemic can affect mental health, though the extent of distress and the temporal trajectories remain understudied. Therefore, one objective of this selective literature review was to provide an overview of the results of longitudinal studies published by June 2021 that examined the impact of the actual COVID-19 pandemic on the mental health of the European population and temporal trajectories over time.

Overall, the results of studies comparing data during the pandemic with data before the pandemic do not provide a consistent picture (see ESM 2): although some European 
Table 2. Protective factors for mental health identified in the selected studies of the selective review

Protective factors

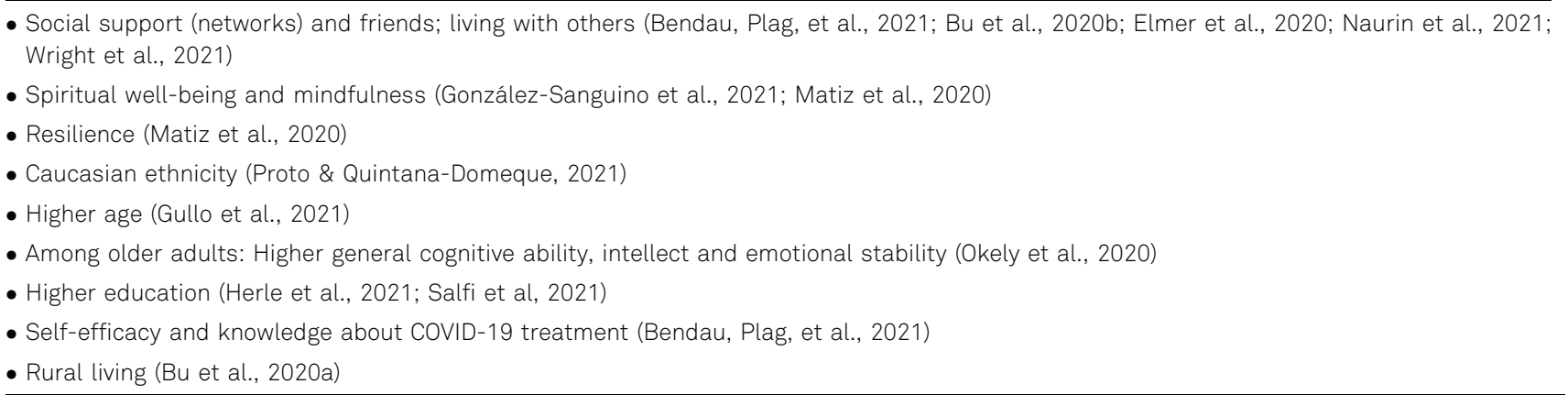

research reported increases in mental distress, anxiety, and depressive symptomatology during the first lockdown 2020 compared to previous years (e.g., Niedzwiedz et al., 2021; Pierce et al., 2020), others failed to find changes in depression severity (Ramiz et al., 2021), or even reported lower depression and anxiety during the first lockdown than before the pandemic (Van der Velden et al., 2021). In line with this, Prati and Mancini (2021) reported in a recent meta-analysis only small lockdown effects on anxiety and depression (mental health symptoms: $g=0.17$ ), pointing to the heterogeneity of methods and study samples included. The search in this meta-analysis was limited to the period from January to June 2020 and thus only to the first lockdown (Prati \& Mancini, 2021). Therefore, these studies and most of our studies in the selective review focused on this time period pointing to rather small effects of the pandemic on mental health compared to pre-pandemic data. The long-term effects of chronic stress exposure during the ongoing pandemic with a highly dynamic and unpredictable course remain to be studied.

In reviewing studies analyzing longitudinal data during the pandemic (see ESM 3), it is striking that some studies report no change (Bendau, Plag, et al., 2021; Groarke et al., 2021), and other studies even report a decrease (Fancourt et al., 2021; Varga et al., 2021) in depressive and anxiety symptomatology. Inline, a study of more than 1,500 participants from the United States which examined longitudinal changes in depression and anxiety weekly from April to June 2020 also found that depression and anxiety scores were high in early April but decreased over time (Shuster et al., 2021). Notably, this study and all our selected studies identified in the databases were restricted to the first lockdown and the following months until summer 2020. Therefore, it is interesting to include two European longitudinal studies that examine the impact of the pandemic on mental health as it progresses and are published predominantly online (COSMO; Betsch et al., 2021; CoviPrev, Santé publique France, 2021). The COVID-19 Snapshot Monitoring (COSMO; https://projekte.uni-erfurt. de/cosmo2020/web/; Betsch et al., 2021) is a serial cross-sectional study in the German general population starting in March 2020, with monthly data collection continuing to run. Data published online showed an increase in tension, anxiety, and depressive symptoms during the second lockdown in Germany and an increase in personal distress (maximum in February 2021 at 64\% and a slow decline to a minimum of $38 \%$ in July 2021). Consistent with this, data from the CoviPrev study in France show an increase in depressive symptoms during the second lockdown (November 2020: 23\%), which remained relatively stable until the third lockdown in April 2021 (22\%) and trended downward in May 2021 (19\%; Santé publique France, 2021).

There are several explanations for these partly contradictory results: First, mental health may depend on COVID-19 incidences, perceived threat, and related restrictions. Interestingly, longitudinal studies have observed improved mental health after reopening in summer 2020 (Fancourt et al., 2021; Varga et al., 2021). This assumption is also supported by the reported online data showing a worsening of symptoms during the second and third lockdown in winter 2020/21 and further relaxation in May and June 2021 (Betsch et al., 2021; Santé publique France, 2021), suggesting that mental health may be strongly dependent on COVID-19-related measures (e.g., lockdown, distancing), and non-related factors. Second, most of the studies retrieved used (online) self-report measures, different instruments, and varying study designs in different samples, which may contribute to the heterogeneity of the results. Third, in line with the multidimensional stressor approach (Brakemeier et al., 2020; Gruber et al., 2021), mental health depends on an interplay of different risk and protective factors. Thus, the pandemic could increase risk in some groups but not in others or even lead to an improvement, so that on average, no changes in mental health can be observed. We, therefore, explored this third point in further analyses of the selected studies by screening them for risk and protective factors. 
In terms of risk factors, we found some variables that were identified as risk factors in studies of earlier epidemics or crises or that are very well explained in the context of the specific nature of the pandemic. The risk factor identified in most studies is young/transition age (see Table 1). This finding can be explained very well by the particular nature of the pandemic: The COVID-19 pandemic has resulted in kindergarten and school closures, affecting more than 1.6 billion children and adolescents worldwide (RavensSieberer et al., 2021). Moreover, restrictions included closures of recreational facilities (even playgrounds), (sports) clubs, and limited personal contact. Limiting important social contacts has generally been shown to be particularly threatening to mental health (Bzdok \& Dunbar, 2020). In this context, adolescence is already described as a period of increased vulnerability, which can be particularly affected by restrictions and isolation, as social contacts and time with peers become more important than staying at home with the family (Brown \& Larson, 2009). Several studies in this review support this assumption $(\mathrm{Bu}$ et al., 2020a, 2020b; González-Sanguino et al., 2021; Niedzwiedz et al., 2021; Pierce et al., 2020; Ramiz et al., 2021; Varga et al., 2021). Consistent with the present findings, another large and recently published German study also points to the significant psychological distress experienced by children and adolescents in the context of the pandemic (Ravens-Sieberer et al., 2021). According to this study, most of 1,040 German children and adolescents aged 11-17 years reported in May and June 2020 that they felt adversely affected by social restrictions (71\%), that conflicts had increased $(27 \%)$ and that learning had become more difficult (65\%). Lower quality of life was reported by $40 \%$ (compared with $15 \%$ before the pandemic), and mental health impairments increased from $18 \%$ prepandemic to $30 \%$ during the pandemic in this young population (Ravens-Sieberer et al., 2021). Unfortunately, few studies included younger children. In most cases, the risk factor of young age relates to emerging adulthood (starting at 18). In line, COSMO data indicate that emerging adults (here 18-29 years) are most impaired (see https://projekte.uni-erfurt.de/cosmo2020/web/explorer/). For example, in January 2021, 69\% of participants aged 18-29 reported personal distress due to COVID-19, compared to only $39 \%$ of participants aged 65 years and older (30-49 years: 60\%; 50-64: 54\%; 65-74: 39\%). In April 2020, this age difference in self-reported distress was less pronounced (18-20 years: 56\%; 30-49: 54\%; 50-64: 40\%; 65-74: 48\%; Betsch et al., 2021). This finding is supported by developmental psychology, which points to the enormous importance of social contact with peers, the increased autonomy from parents, significant shifts in social roles, and relationship instability per se (Sussman \& Arnett, 2014). A recent study also appears alarming, indicating that the rate of university students suffering from suicidal ideation was twice as high in 2020 compared to previous years (Brailovskaia et al., 2021).

In contrast to young age, the results for older adults are rather mixed. On the one hand, two studies in our selective review suggest a deterioration in mental health (Ramiz et al., 2021) and increased loneliness, especially among those living alone (Stolz et al., 2021). On the other hand, longitudinal data on older individuals showed comparable life satisfaction and loneliness in Sweden since 2015 (Kivi et al., 2021). In addition, older adults reported overall less distress and loneliness and even lower perceived risk for a COVID-19 infection than younger individuals in several cross-sectional studies (Buecker et al., 2020; McGinty et al., 2020; Schäfer et al., 2020). Accordingly, the COSMO data also show older adults (65-74 years) to be almost consistently the least distressed of all age groups from March 2020 to September 2021 (see https://projekte.uni-erfurt. de/cosmo2020/web/explorer/).

When interpreting these results, one should bear in mind that most of the current surveys were conducted online and may not reach older individuals living alone or in nursing homes who have few resources. Adding telephone interviews and sending out paper-pencil questionnaires might be helpful to overcome this potential bias. However, for example, in April 2020, adults in a representative German sample aged 65 years and above reported depression, anxiety, somatization, and psychological distress, which were in the normative range, and telephone interview results did not suggest an increase in loneliness $(13.1 \%$; $8.8 \%$ in men and $16.3 \%$ in women; Röhr et al., 2020).

Concerning social risk factors, living alone, low social support, and perceived loneliness have been identified as risk factors in some studies reviewed here (e.g., Bu et al., 2020b; Elmer et al., 2020). This is not surprising, as subjective feelings of loneliness are associated with depressive symptoms and chronic illness independently of crises such as the pandemic (Bzdok \& Dunbar, 2020; Cacioppo \& Patrick, 2008; Cacioppo et al., 2006; Erzen \& Çikrikci, 2018). Notably, in Europe, nationality generally has a stronger impact on perceived loneliness than age, with highest prevalence in Eastern Europe (Yang \& Victor, 2011), suggesting a differential distribution of this risk factor across the EU. However, the studies reviewed here were exclusively conducted in Western, Northern, and Southern Europe, with a strong predominance of data from the United Kingdom for the general population.

Other social risk factors for impaired mental health identified here were: female (with the most robust evidence, see Table 1), living with young children (Pierce et al., 2020), unemployment, low education, and low income (e.g., Bu et al., 2020a, 2020b). These risk factors have also been identified in other studies (e.g., from the United States; 
Shuster et al., 2021) and underscore the importance of targeting support (prevention and treatment) to individuals with one or even more of these risk factors (e.g., mothers of young children with low income; cf. Brakemeier et al., 2020). Notably, pre-pandemic employment and having a higher degree were associated with poorer mental health (e.g., Naurin et al., 2021; Pierce et al., 2020), suggesting more complex interactions between employment (e.g., fear of job loss; see also Boyce et al., 2018), education, and mental health. Importantly, four studies reported that non-Caucasians were particularly at risk. Ethnic and racial minorities face chronic stressors per se, that is, discrimination, lower education and income, and poorer access to and utilization of health care. Moreover, some are overrepresented in the essential work settings (e.g., healthcare, public transport) and thus are also at higher risk for COVID-19 infection (Wadhera et al., 2020).

Regarding the physical and mental health risk factors identified in the studies, low physical health before the pandemic appears to be associated with lower mental health during the pandemic (e.g., Ramiz et al. 2021; Varga et al., 2021). This is also true for severe or chronic (pre-pandemic) mental disorders (e.g., Pan et al., 2021) and substance use (Bendau, Plag, et al., 2021), as well as elevated worries (Elmer et al., 2020) and perceived distress (Savage et al., 2021).

Because mental disorders are common - the World Health Organization (Vos et al., 2016) reported an estimated 110 million (12\%) individuals with mental disorders in 2015 and an additional 27 million individuals with substance abuse in Europe - it is especially important to provide intensive treatment services to patients with mental disorders. It is well-known that very few individuals with a mental disorder use health services $(18.9 \%$ in Germany, Mack et al., 2014; 25.7\% in Europe, Alonso et al., 2004). Thus, it seems essential to ensure that these individuals can be offered concrete and timely help in crises such as the pandemic to prevent chronic disease progression. There is an urgent need for action here. Some researchers suggest a possible increase in stress-related disorders (such as depression, anxiety disorders, and PTSD; Horesh \& Brown, 2020; Vindegaard \& Benros, 2020), psychotic (Brown et al., 2020), and borderline personality disorders (Wurman et al., 2020). It is also suggested that individuals suffering from a substance use disorder may be more susceptible to COVID-19 infection and relapse (Volkow, 2020). Whether the prevalence of mental disorders will increase in the long term is not yet foreseeable.

Only one of the studies reviewed here suggests that COVID-19 infection itself, intensive care unit admission, and long-term post-COVID consequences may negatively impact mental health (Romero-Duarte et al., 2021). Crosssectional data also indicated that COVID-19 survivors showed elevated levels of depression, anxiety and posttraumatic stress 1 month after hospital discharge (Mazza et al., 2020). Accordingly, following COVID-19 infection, about $35 \%$ of outpatients and $87 \%$ of inpatients reported persisting symptoms such as fatigue, dyspnea, and neuropsychological symptoms (Carfi et al., 2020; Tenforde et al., 2020). Interestingly, there might also be an association between (neuro-) inflammatory processes and neuropsychological impairments that needs further investigation (Mazza et al., 2020). Some authors suggest a prolonged post-COVID syndrome (time criterion is 6 months) or post-infectious fatigue, which might be independent of initial infection severity and more prominent in women (Townsend et al., 2020), and which could be comparable to the post-intensive care syndrome (Lamprecht, 2020; Rawal et al., 2017).

In contrast to risk factors, only a few studies retrieved by the present search have focused on protective factors. Individual studies reported that higher resilience can lead to better mental health (Matiz et al., 2020), and that social support and living with others (e.g., Bendau, Plag, et al., 2021; Wright et al., 2021) are protective factors, highlighting the importance of social support for mental well-being. Although physical (rather than social!) distancing measures are important for coping with the pandemic, flexible and comprehensible adaptation of the interventions following scientific recommendations should be applied to foster social contact (Brakemeier et al., 2020). Moreover, interventions promoting mindfulness, resilience, functional emotion regulation, self-efficacy, and COVID-19 knowledge should be provided and evaluated, especially in risk populations (see above). Although first proposals for promoting resilience during the pandemic have already been made (Albott et al., 2020; Prime et al., 2020), there is still a need for research on how individuals cope with the multifactorial stressor and what factors prevent mental disorders. The relationships between resilience and mental health are dynamic and complex (for an overview, see Ungar \& Theron, 2020). In this context, the European research project DynaCORE (Dynamic Modeling of Corona Resilience) identifies resilience factors to derive recommendations. First results indicate that mental health depends particularly on a positive appraisal style, that is, how the threat from COVID-19 and crisis outcomes is perceived (Veer et al., 2021). In addition, Veer and colleagues concluded that people who tend to see positive aspects and accept unchangeable facts have fewer mental health problems (in line with Matiz et al., 2020). In line, positive mental health in October 2019 predicted a lower burden by the pandemic in March 2020, and this effect was mediated by a higher perceived sense of control (Brailovskaia \& Margraf, 2020).

This selective review has several limitations. The COVID-19 pandemic represents an ongoing mental health 
challenge (Brakemeier et al., 2020; Gruber et al., 2021; Moreno et al., 2020), and the studies in the selective review were limited by the search terms and inclusion criteria. This selection resulted in studies that were limited in terms of the time period studied (mostly focusing only on the first lockdown and the immediate aftermath), representativeness in terms of the age range (mostly not including infants and elementary school children and the very old adults), countries and other diversities studied, and design (mostly online studies with unrepresentative samples).

In summary, the impact of the pandemic on mental health appears to depend on COVID-19-related measures as well as on an interplay of risk and protective factors that are not yet fully understood. Evidence suggests that after the unexpected initial lockdown, which on average did have a small initial negative impact on mental health, Europeans subsequently coped quite well with the pandemic and the measures, resulting in recovery. However, the long-term consequences cannot yet be predicted, as there is a lack of high-quality studies that include all age groups. The duration of the stressor could well be decisive, with subgroups of people with one or even several risk factors, in particular, being exposed to a higher vulnerability to mental health problems. However, identified protective factors also point to variables that can strengthen people for future crises. Overall, it seems helpful to see the pandemic, apart from the existential crisis, also as an opportunity to raise awareness of mental health issues in general, to improve and personalize existing interventions taking into account risk groups, and to promote psychosocial interventions to support mental health at the population level. The pandemic will likely make society more aware of the existence of mental health problems, which could counteract the stigmatization of mental disorders and lead to increased help-seeking behavior by those affected. To this end, staged models of individualized prevention and intervention, including digital mental health (see Brakemeier et al., 2020), should be developed and intensively applied in Europe and worldwide.

\section{Electronic Supplementary Material}

The electronic supplementary materials are available with the online version of the article at https://doi.org/ 10.1027/1016-9040/a000465

ESM 1. Records retrieved on June 7, 2021, for search-terms COVID-19, mental health, longitudinal, and Europe.

ESM 2. Longitudinal European studies, including prepandemic and pandemic data identified in the selective review.

ESM 3. Longitudinal European studies, including pandemic data identified in the selective review.

\section{References}

*Included in the selective review.

Albott, C. S., Wozniak, J. R., McGlinch, B. P., Wall, M. H., Gold, B. S. \& Vinogradov, S. (2020). Battle buddies: Rapid deployment of a psychological resilience intervention for health care workers during the COVID-19 pandemic. Anesthesia and Analgesia, 131(1), 43-54. https://doi.org/10.1213/ANE.0000000000004912

*Alivernini, F., Manganelli, S., Girelli, L., Cozzolino, M., Lucidi, F., \& Cavicchiolo, E. (2021). Physical distancing behavior: the role of emotions, personality, motivations, and moral decision-making. Journal of Pediatric Psychology, 46(1), 15-26. https://doi.org/ 10.1093/jpepsy/jsaa122

Alonso, J., Angermeyer, M. C., Bernert, S., Bruffaerts, R., Brugha, T. S., Bryson, H., De Girolamo, G., De Graaf, R., Demyttenaere, K., Gasquet, I., Haro, J. M., Katz, S. J., Kessler, R. C., Kovess, V., Lépine, J. F., Ormel, J., Polidori, G., Russo, L. J., Vilagut, G., .. Vollebergh, W. A. M. (2004). Use of mental health services in Europe: Results from the European Study of the Epidemiology of Mental Disorders (ESEMeD) project. Acta Psychiatrica Scandinavica, Supplementum, 109(420), 47-54. https://doi. org/10.1111/j.1600-0047.2004.00330.x

*Bendau, A., Kunas, S. L., Wyka, S., Petzold, M. B., Plag, J., Asselmann, E., \& Ströhle, A. (2021). Longitudinal changes of anxiety and depressive symptoms during the COVID-19 pandemic in Germany: The role of pre-existing anxiety, depressive, and other mental disorders. Journal of Anxiety Disorders, 79 https://doi.org/10.1016/j.janxdis.2021.102377

*Bendau, A., Plag, J., Kunas, S., Wyka, S., Ströhle, A., \& Petzold, M. B. (2021). Longitudinal changes in anxiety and psychological distress, and associated risk and protective factors during the first three months of the COVID-19 pandemic in Germany. Brain and Behavior, 11(2), Article e01964. https://doi.org/10.1002/ brb3.1964

Betsch, C., Korn, L., Felgendreff, L., Eitze, S., Schmid, P. Sprengholz, P., Siegers, R., Goldhahn, L., Wieler, L., Schmich, P., Stollorz, V., Ramharter, M., Bosnjak, M., Omer, S. B., Thaiss, H., De Bock, F., \& Von Rüden, U. (2021). COVID-19 Snapshot Monitoring (COSMO Germany) - Wave 43 [Dataset]. PsychArchives. https://doi.org/10.23668/PSYCHARCHIVES.4857

Boyce, C. J., Delaney, L., \& Wood, A. M. (2018). The great recession and subjective well-being: How did the life satisfaction of people living in the United Kingdom change following the financial crisis? PLoS One, 13(8), Article e0201215. https://doi. org/10.1371/journal.pone.0201215

Brailovskaia, J., \& Margraf, J. (2020). Predicting adaptive and maladaptive responses to the Coronavirus (COVID-19) outbreak: A prospective longitudinal study. International Journal of Clinical and Health Psychology, 20(3), 183-191. https://doi.org/ 10.1016/j.ijchp.2020.06.002

Brailovskaia, J., Teismann, T., Friedrich, S., Schneider, S., \& Margraf, J. (2021). Suicide ideation during the COVID-19 outbreak in German university students: Comparison with pre-COVID 19 rates. Journal of Affective Disorders Reports, 6, Article 100228. https://doi.org/10.1016/j.jadr.2021.100228

Brakemeier, E.-L., Wirkner, J., Knaevelsrud, C., Wurm, S., Christiansen, H., Lueken, U., \& Schneider, S. (2020). Die COVID-19-Pandemie als Herausforderung für die psychische Gesundheit [The COVID-19 pandemic as a challenge to mental health. Findings and implications for research and practice from the perspective of clinical psychology and psychotherapy]. Zeitschrift für Klinische Psychologie und Psychotherapie, 49, 1-31. https://doi.org/10.1026/1616-3443/a000574

Brown, B. B., \& Larson, J. (2009). Peer relationships in adolescence. In R. M. Lerner \& L. Steinberg (Eds.), Handbook of adolescent psychology: Contextual influences on adolescent 
development (pp. 74-103). Wiley. https://doi.org/10.1002/ 9780470479193.adlpsy002004

Brown, E., Gray, R., Lo Monaco, S., O’Donoghue, B., Nelson, B., Thompson, A., Francey, S., \& McGorry, P. (2020). The potential impact of COVID-19 on psychosis: A rapid review of contemporary epidemic and pandemic research. Schizophrenia Research, 222, 79-87. https://doi.org/10.1016/J.SCHRES.2020. 05.005

*Bu, F., Steptoe, A., \& Fancourt, D. (2020a). Who is lonely in lockdown? Cross-cohort analyses of predictors of loneliness before and during the COVID-19 pandemic. Public Health, 186, 31-34. https://doi.org/10.1016/j.puhe.2020.06.036

Bu, F., Steptoe, A., \& Fancourt, D. (2020b). Loneliness during a strict lockdown: Trajectories and predictors during the COVID19 pandemic in 38,217 United Kingdom adults. Social Science and Medicine, 265, Article 113521. https://doi.org/10.1016/ j.socscimed.2020.113521

*Buecker, S., Horstmann, K. T., Krasko, J., Kritzler, S., Terwiel, S., Kaiser, T., \& Luhmann, M. (2020). Changes in daily loneliness for German residents during the first four weeks of the COVID19 pandemic. Social Science \& Medicine, 265, Article 113541. https://doi.org/10.1016/j.socscimed.2020.113541

Bzdok, D., \& Dunbar, R. I. M. (2020). The neurobiology of social distance. Trends in Cognitive Sciences, 24(9), 717-733. https:// doi.org/10.1016/j.tics.2020.05.016

Cacioppo, J. T., Hughes, M. E., Waite, L. J., Hawkley, L. C., \& Thisted, R. A. (2006). Loneliness as a specific risk factor for depressive symptoms: Cross-sectional and longitudinal analyses. Psychology and Aging, 21(1), 140-151. https://doi.org/ 10.1037/0882-7974.21.1.140

Cacioppo, J. T., \& Patrick, W. (2008). Loneliness: Human nature and the need for social connection. W. W. Norton.

Carfi, A., Bernabei, R., \& Landi, F. (2020). Persistent symptoms in patients after acute COVID-19. Journal of the American Medical Association, 324(6), 603-605. https://doi.org/10.1001/jama. 2020.12603

*Castellini, G., Rossi, E., Cassioli, E., Sanfilippo, G., Innocenti, M., Gironi, V., Silvestri, C., Voller, F., \& Ricca, V. (2021). A longitudinal observation of general psychopathology before the COVID-19 outbreak and during lockdown in Italy. Journal of Psychosomatic Research, 141, Article 110328. https://doi.org/ 10.1016/j.jpsychores.2020.110328

Davidson, B., Schmidt, E., Mallar, C., Mahmoud, F., Rothenberg, W., Hernandez, J. M. B., Jent, J., Delamater, A., \& Natale, R. (2021). Risk and resilience of well-being in caregivers of young children in response to the COVID-19 pandemic. Translational Behavioral Medicine, 11(2), 305-313. https://doi.org/10.1093/ TBM/IBAA124

*Ehrler, M., Werninger, I., Schnider, B., Eichelberger, D. A., Naef, N., Disselhoff, V., Kretschmar, O., Hagmann, C. F., Latal, B., \& Wehrle, F. M. (2021). Impact of the COVID-19 pandemic on children with and without risk for neurodevelopmental impairments. Acta Paediatrica, 110(4), 1281-1288. https://doi.org/ 10.1111/apa.15775

*Elmer, T., Mepham, K., \& Stadtfeld, C. (2020). Students under lockdown: Comparisons of students' social networks and mental health before and during the COVID-19 crisis in Switzerland. PLoS One, 15(7), Article e0236337. https://doi. org/10.1371/journal.pone.0236337

Erzen, E., \& Çikrikci, Ö. (2018). The effect of loneliness on depression: A meta-analysis. International Journal of Social Psychiatry, 64(5), 427-435. https://doi.org/10.1177/ 0020764018776349

European Commission. (2021, June 10). Timeline of EU action. https://ec.europa.eu/info/live-work-travel-eu/health/coronavirus-response/timeline-eu-action_en
*Evans, S., Alkan, E., Bhangoo, J. K., Tenenbaum, H., \& Ng-Knight, T. (2021). Effects of the COVID-19 lockdown on mental health, wellbeing, sleep, and alcohol use in a UK student sample. Psychiatry research, 298, Article 113819. https://doi.org/ 10.1016/j.psychres.2021.113819

*Ezpeleta, L., Navarro, J. B., de la Osa, N., Trepat, E., \& Penelo, E. (2020). Life conditions during COVID-19 lockdown and mental health in Spanish adolescents. International Journal of Environmental Research and Public Health, 17(19), 1-13. https:// doi.org/10.3390/ijerph17197327

*Fancourt, D., Steptoe, A., \& Bu, F. (2021). Trajectories of anxiety and depressive symptoms during enforced isolation due to COVID-19 in England: A longitudinal observational study. The Lancet Psychiatry, 8(2), 141-149. https://doi.org/10.1016/ S2215-0366(20)30482-X

Forbes, M. K., \& Krueger, R. F. (2019). The great recession and mental health in the United States. Clinical Psychological Science, 7(5), 900-913. https://doi.org/10.1177/2167702619859337

*González-Sanguino, C., Ausín, B., Castellanos, M. A., Saiz, J., \& Muñoz, M. (2021). Mental health consequences of the COVID19 outbreak in Spain. A longitudinal study of the alarm situation and return to the new normality. Progress in NeuroPsychopharmacology and Biological Psychiatry, 107, Article 110219. https://doi.org/10.1016/j.pnpbp.2020.110219

*Groarke, J. M., McGlinchey, E., McKenna-Plumley, P. E., Berry, E., Graham-Wisener, L., \& Armour, C. (2021). Examining temporal interactions between loneliness and depressive symptoms and the mediating role of emotion regulation difficulties among UK residents during the COVID-19 lockdown: Longitudinal results from the COVID-19 psychological wellbeing study. Journal of Affective Disorders, 285, 1-9. https://doi.org/ 10.1016/j.jad.2021.02.033

Gruber, J., Prinstein, M. J., Clark, L. A., Rottenberg, J., Abramowitz, J. S., Albano, A. M., Aldao, A., Borelli, J. L., Chung, T., Davila, J., Forbes, E. E., Gee, D. G., Hall, G. C. N., Hallion, L. S., Hinshaw, S. P., Hofmann, S. G., Hollon, S. D., Joormann, J., Kazdin, A. E., ... Weinstock, L. M. (2021). Mental health and clinical psychological science in the time of COVID-19: Challenges, opportunities, and a call to action. American Psychologist, 76(3), 409-426. https://doi.org/10.1037/ amp0000707

*Gullo, S., Misici, I., Teti, A., Liuzzi, M., \& Chiara, E. (2021). Going through the lockdown: A longitudinal study on the psychological consequences of the coronavirus pandemic. Research in Psychotherapy, 23(3), Article 494. https://doi.org/10.4081/ ripppo. 2020.494

Hammen, C., Kim, E. Y., Eberhart, N. K., \& Brennan, P. A. (2009). Chronic and acute stress and the prediction of major depression in women. Depression and Anxiety, 26(8), 718-723. https:// doi.org/10.1002/da.20571

*Herle, M., Smith, A. D., Bu, F., Steptoe, A., \& Fancourt, D. (2021). Trajectories of eating behavior during COVID-19 lockdown: Longitudinal analyses of 22,374 adults. Clinical Nutrition ESPEN, 42, 158-165. https://doi.org/10.1016/j.clnesp.2021. 01.046

Horesh, D., \& Brown, A. D. (2020). Covid-19 response: Traumatic stress in the age of COVID-19: A call to close critical gaps and adapt to new realities. Psychological Trauma: Theory, Research, Practice, and Policy, 12(4), 331-335. https://doi.org/10.1037/ TRA0000592

*Janssen, L. H. C., Kullberg, M. L., Verkuil, B., van Zwieten, N., Wever, M. C. M., van Houtum, L. A. E. M., Wentholt, W. G. M., \& Elzinga, B. M. (2020). Does the COVID-19 pandemic impact parents' and adolescents' well-being? An EMA-study on daily affect and parenting. PLoS One, 15(10), Article e0240962. https://doi.org/10.1371/journal.pone.0240962 
Katikireddi, S. V., Niedzwiedz, C. L., \& Popham, F. (2012). Trends in population mental health before and after the 2008 recession: A repeat cross-sectional analysis of the 1991-2010 Health Surveys of England. BMJ Open, 2(5), Article 1790. https://doi.org/10.1136/bmjopen-2012-001790

*Kivi, M., Hansson, I., \& Bjälkebring, P. (2021). Up and about: Older adults' well-being during the COVID-19 pandemic in a swedish longitudinal study. The Journals of Gerontology. Series B, Psychological Sciences and Social Sciences, 76(2), e4-e9. https://doi.org/10.1093/geronb/gbaa084

Lamprecht, B. (2020). Is there a post-COVID syndrome? Pneumologe, 17, 398-405. https://doi.org/10.1007/s10405-02000347-0

Lee, A. M., Wong, J. G. W. S., McAlonan, G. M., Cheung, V., Cheung, C., Sham, P. C., Chu, N. M., Wong, P. C., Tsang, K. W. T., \& Chua, S. E. (2007). Stress and psychological distress among SARS survivors 1 year after the outbreak. Canadian Journal of Psychiatry, 52(4), 233-240. https://doi.org/10.1177/ 070674370705200405

Mack, S., Jacobi, F., Gerschler, A., Strehle, J., Höfler, M., Busch, M. A., Maske, U. E., Hapke, U., Seiffert, I., Gaebel, W., Zielasek, J., Maier, W., \& Wittchen, H. U. (2014). Self-reported utilization of mental health services in the adult German population evidence for unmet needs? Results of the DEGS1-Mental health module (DEGS1-MH). International Journal of Methods in Psychiatric Research, 23(3), 289-303. https://doi.org/10.1002/ mpr.1438

Marin, M. F., Lord, C., Andrews, J., Juster, R. P., Sindi, S., Arsenault-Lapierre, G., Fiocco, A. J., \& Lupien, S. J. (2011). Chronic stress, cognitive functioning and mental health. Neurobiology of Learning and Memory, 96(4), 583-595. https://doi. org/10.1016/j.nlm.2011.02.016

*Matiz, A., Fabbro, F., Paschetto, A., Cantone, D., Paolone, A. R., \& Crescentini, C. (2020). Positive impact of mindfulness meditation on mental health of female teachers during the COVID-19 outbreak in Italy. International Journal of Environmental Research and Public Health, 17(18), 1-22. https://doi.org/ 10.3390/ijerph17186450

Mazza, M. G., De Lorenzo, R., Conte, C., Poletti, S., Vai, B., Bollettini, I., Melloni, E. M. T., Furlan, R., Ciceri, F., RovereQuerini, P., \& Benedetti, F. (2020). Anxiety and depression in COVID-19 survivors: Role of inflammatory and clinical predictors. Brain, Behavior, and Immunity, 89, 594-600. https://doi. org/10.1016/j.bbi.2020.07.037

McEwen, B. S., \& Stellar, E. (1993). Stress and the individual: Mechanisms leading to disease. Archives of Internal Medicine, 153(18), 2093-2101. https://doi.org/10.1001/archinte.1993. 00410180039004

McGinty, E. E., Presskreischer, R., Han, H., \& Barry, C. L. (2020). Psychological distress and loneliness reported by US adults in 2018 and April 2020. Journal of the American Medical Association, 324(1), 93-94. https://doi.org/10.1001/jama.2020.9740

*Naurin, E., Markstedt, E., Stolle, D., Enström, D., Wallin, A., Andreasson, I., Attebo, B., Eriksson, O., Martinsson, K., Elden, H., Linden, K., \& Sengpiel, V. (2021). Pregnant under the pressure of a pandemic: A large-scale longitudinal survey before and during the COVID-19 outbreak. European Journal of Public Health, 31(1), 7-13. https://doi.org/10.1093/eurpub/ ckaa223

*Niedzwiedz, C. L., Green, M. J., Benzeval, M., Campbell, D., Craig, P., Demou, E., Leyland, A., Pearce, A., Thomson, R., Whitley, E., \& Katikireddi, S. V. (2021). Mental health and health behaviours before and during the initial phase of the COVID-19 lockdown: Longitudinal analyses of the UK Household Longitudinal Study. Journal of Epidemiology and Community Health, 75(3), 224-231. https://doi.org/10.1136/jech-2020-215060
*Okely, J. A., Corley, J., Welstead, M., Taylor, A. M., Page, D., Skarabela, B., Redmond, P., Cox, S. R., \& Russ, T. C. (2020). Change in physical activity, sleep quality, and psychosocial variables during COVID-19 lockdown: Evidence from the Lothian Birth Cohort 1936. International Journal of Environmental Research and Public Health, 18(1), Article 210. https://doi.org/ 10.3390/ijerph18010210

*Pan, K. Y., Kok, A. A. L., Eikelenboom, M., Horsfall, M., Jörg, F., Luteijn, R. A., Rhebergen, D., van Oppen, P., Giltay, E. J., \& Penninx, B. W. J. H. (2021). The mental health impact of the COVID-19 pandemic on people with and without depressive, anxiety, or obsessive-compulsive disorders: A longitudinal study of three Dutch case-control cohorts. The Lancet Psychiatry, 8(2), 121-129. https://doi.org/10.1016/S2215-0366(20) 30491-0

*Pierce, M., Hope, H., Ford, T., Hatch, S., Hotopf, M., John, A., Kontopantelis, E., Webb, R., Wessely, S., McManus, S., \& Abel, K. M. (2020). Mental health before and during the COVID-19 pandemic: A longitudinal probability sample survey of the UK population. The Lancet Psychiatry, 7(10), 883-892. https://doi. org/10.1016/S2215-0366(20)30308-4

Prati, G., \& Mancini, A. D. (2021). The psychological impact of COVID-19 pandemic lockdowns: A review and meta-analysis of longitudinal studies and natural experiments. Psychological Medicine, 51(2), 201-211. https://doi.org/10.1017/ S0033291721000015

*Prime, H., Wade, M., \& Browne, D. T. (2020). Risk and resilience in family well-being during the COVID-19 pandemic. American Psychologist, 75(5), 631-643. https://doi.org/10.1037/ amp0000660

*Proto, E., \& Quintana-Domeque, C. (2021). COVID-19 and mental health deterioration by ethnicity and gender in the UK. PloS One, 16(1), Article e0244419. https://doi.org/10.1371/journal. pone.0244419

*Ramiz, L., Contrand, B., Rojas Castro, M. Y., Dupuy, M., Lu, L., Sztal-Kutas, C., \& Lagarde, E. (2021). A longitudinal study of mental health before and during COVID-19 lockdown in the French population. Globalization and Health, 17(1), Article 29 https://doi.org/10.1186/s12992-021-00682-8

Ravens-Sieberer, U., Kaman, A., Erhart, M., Devine, J., Schlack, R., \& Otto, C. (2021). Impact of the COVID-19 pandemic on quality of life and mental health in children and adolescents in Germany. European Child \& Adolescent Psychiatry, 1-11. Advance online publication. https://doi.org/10.1007/s00787021-01726-5

Rawal, G., Yadav, S., \& Kumar, R. (2017). Post-intensive care syndrome: An overview. Journal of Translational Internal Medicine, 5(2), 90-92. https://doi.org/10.1515/jtim-2016-0016

Röhr, S., Reininghaus, U., \& Riedel-Heller, S. G. (2020). Mental wellbeing in the German old age population largely unaltered during COVID-19 lockdown: results of a representative survey. BMC Geriatrics, 20(1), Article 489. https://doi.org/10.1186/ s12877-020-01889-x

*Romero-Duarte, Á., Rivera-Izquierdo, M., Guerrero-Fernández de Alba, I., Pérez-Contreras, M., Fernández-Martínez, N. F., RuizMontero, R., Serrano-Ortiz, Á., González-Serna, R. O., SalcedoLeal, I., Jiménez-Mejías, E., \& Cárdenas-Cruz, A. (2021). Sequelae, persistent symptomatology and outcomes after COVID-19 hospitalization: The ANCOHVID multicentre 6-month follow-up study. BMC Medicine, 19(1), Article 129. https://doi. org/10.1186/s12916-021-02003-7

*Salfi, F., D’Atri, A., Tempesta, D., \& Ferrara, M. (2021). Sleeping under the waves: A longitudinal study across the contagion peaks of the COVID-19 pandemic in Italy. Journal of Sleep Research, 30(5), Article e13313. https://doi.org/10.1111/jsr. 13313 
Santé publique France. (2021, June 19). CoviPrev: une enquête pour suivre l'évolution des comportements et de la santé mentale pendant l'épidémie de COVID-19. https://www.santepubliquefrance.fr/etudes-et-enquetes/coviprev-une-enquete-poursuivre-l-evolution-des-comportements-et-de-la-sante-mentalependant-l-epidemie-de-covid-19\#block-249162

*Savage, M. J., Hennis, P. J., Magistro, D., Donaldson, J., Healy, L. C., \& James, R. M. (2021). Nine months into the COVID-19 pandemic: A longitudinal study showing mental health and movement behaviours are impaired in UK students. International Journal of Environmental Research and Public Health, 18 (6), 1-10. https://doi.org/10.3390/ijerph18062930

*Savolainen, I., Oksa, R., Savela, N., Celuch, M., \& Oksanen, A. (2021). COVID-19 anxiety - A longitudinal survey study of psychological and situational risks among Finnish workers. International Journal of Environmental Research and Public Health, 18(2), Article 794. https://doi.org/10.3390/ijerph18020794

Schäfer, S. K., Sopp, M. R., Schanz, C. G., Staginnus, M., Göritz, A. S., \& Michael, T. (2020). Impact of COVID-19 on public mental health and the buffering effect of a sense of coherence. Psychotherapy and Psychosomatics, 89(6), 386-392. https:// doi.org/10.1159/000510752

Shamseer, L., Moher, D., Clarke, M., Ghersi, D., Liberati, A., Petticrew, M., Shekelle, P., Stewart, L. A., Altman, D. G., Booth, A., Chan, A. W., Chang, S., Clifford, T., Dickersin, K., Egger, M., Gøtzsche, P. C., Grimshaw, J. M., Groves, T., Helfand, M., ... Whitlock, E. (2015). Preferred reporting items for systematic review and meta-analysis protocols (prisma-p) 2015: Elaboration and explanation. British Medical Journal, 350, Article g7647. https://doi.org/10.1136/bmj.g7647

Shuster, A., O’Brien, M., Luo, Y., Berner, L. A., Perl, O., Heflin, M., Kulkarni, K., Chung, D., Na, S., Fiore, V. G., \& Gu, X. (2021). Emotional adaptation during a crisis: Decline in anxiety and depression after the initial weeks of COVID-19 in the United States. Translational Psychiatry, 11(1), Article 435. https://doi. org/10.1038/S41398-021-01552-Y

Smoller, J.W. (2016). The genetics of stress-related disorders: PTSD, depression, and anxiety disorders. Neuropsychopharmacology, 41(1), 297-319. https://doi.org/10.1038/npp.2015.266

*Stolz, E., Mayerl, H., \& Freidl, W. (2021). The impact of COVID-19 restriction measures on loneliness among older adults in Austria. European Journal of Public Health, 31(1), 44-49. https://doi.org/10.1093/eurpub/ckaa238

Sussman, S. S., \& Arnett, J. J. (2014). Emerging adulthood: Developmental period facilitative of the addictions. Evaluation \& The Health Professions, 37(2), 147-155. https://doi.org/ 10.1177/0163278714521812

Tenforde, M. W., Kim, S. S., Lindsell, C. J., Billig Rose, E., Shapiro, N. I., Files, D. C., Gibbs, K. W., Erickson, H. L., Steingrub, J. S., Smithline, H. A., Gong, M. N., Aboodi, M. S., Exline, M. C., Henning, D. J., Wilson, J. G., Khan, A., Qadir, N., Brown, S. M., Peltan, I. D., ... Wu, M. J. (2020). Symptom duration and risk factors for delayed return to usual health among outpatients with COVID-19 in a multistate health care systems network - United States, March-June 2020. Morbidity and Mortality Weekly Report, 69(30), 993-998. https://doi.org/10.15585/mmwr.mm6930e1

Townsend, L., Dyer, A. H., Jones, K., Dunne, J., Mooney, A., Gaffney, F., O'Connor, L., Leavy, D., O'Brien, K., Dowds, J., Sugrue, J. A., Hopkins, D., Martin-Loeches, I., Ni Cheallaigh, C., Nadarajan, P., McLaughlin, A. M., Bourke, N. M., Bergin, C., O'Farrelly, C., ... Conlon, N. (2020). Persistent fatigue following SARS-CoV-2 infection is common and independent of severity of initial infection. PLoS One, 15(11), Article e0240784. https:// doi.org/10.1371/journal.pone.0240784

Ungar, M., \& Theron, L. (2020). Resilience and mental health: how multisystemic processes contribute to positive outcomes. The
Lancet. Psychiatry, 7(5), 441-448. https://doi.org/10.1016/ S2215-0366(19)30434-1

*Van der Velden, P. G., Contino, C., Das, M., van Loon, P., \& Bosmans, M. W. G. (2020). Anxiety and depression symptoms, and lack of emotional support among the general population before and during the COVID-19 pandemic. A prospective national study on prevalence and risk factors. Journal of Affective Disorders, 277, 540-548. https://doi.org/10.1016/ j.jad.2020.08.026

*Van der Velden, P. G., Hyland, P., Contino, C., von Gaudecker, H. M., Muffels, R., \& Das, M. (2021). Anxiety and depression symptoms, the recovery from symptoms, and loneliness before and after the COVID-19 outbreak among the general population: Findings from a Dutch population-based longitudinal study. PLoS One, 16(1), Article e0245057. https://doi.org/ 10.1371/journal.pone.0245057

*Varga, T. V., Bu, F., Dissing, A. S., Elsenburg, L. K., Bustamante, J. J. H., Matta, J., van Zon, S. K. R., Brouwer, S., Bültmann, U., Fancourt, D., Hoeyer, K., Goldberg, M., Melchior, M., Strandberg-Larsen, K., Zins, M., Clotworthy, A., \& Rod, N. H. (2021). Loneliness, worries, anxiety, and precautionary behaviours in response to the COVID-19 pandemic: A longitudinal analysis of 200, 000 Western and Northern Europeans. The Lancet Regional Health - Europe, 2, Article 100020. https://doi. org/10.1016/j.lanepe.2020.100020

Veer, I. M., Riepenhausen, A., Zerban, M., Wackerhagen, C., Puhlmann, L. M. C., Engen, H., Köber, G., Bögemann, S. A., Weermeijer, J., Uścitko, A., Mor, N., Marciniak, M. A., Askelund, A. D., Al-Kamel, A., Ayash, S., Barsuola, G., BartkuteNorkuniene, V., Battaglia, S., Bobko, Y., ... Kalisch, R. (2021). Psycho-social factors associated with mental resilience in the Corona lockdown. Translational Psychiatry, 11(1), Article 67. https://doi.org/10.1038/s41398-020-01150-4

Vindegaard, N., \& Benros, M. E. (2020). COVID-19 pandemic and mental health consequences: Systematic review of the current evidence. Brain, Behavior, and Immunity, 89, 531-542. https:// doi.org/10.1016/j.bbi.2020.05.048

Volkow, N. D. (2020). Collision of the COVID-19 and addiction epidemics. Annals of Internal Medicine, 173(1), 61-62. https:// doi.org/10.7326/M20-1212

Vos, T., Allen, C., Arora, M., Barber, R. M., Brown, A., Carter, A., Casey, D. C., Charlson, F. J., Chen, A. Z., Coggeshall, M., Cornaby, L., Dandona, L., Dicker, D. J., Dilegge, T., Erskine, H. E., Ferrari, A. J., Fitzmaurice, C., Fleming, T., Forouzanfar, M. H., ... Zuhlke, L. J. (2016). Global, regional, and national incidence, prevalence, and years lived with disability for 310 diseases and injuries, 1990-2015: A systematic analysis for the Global Burden of Disease Study 2015. The Lancet, 388(10053), 1545-1602. https://doi.org/10.1016/S0140-6736(16)31678-6

Wadhera, R. K., Wadhera, P., Gaba, P., Figueroa, J. F., Joynt Maddox, K. E., Yeh, R. W., \& Shen, C. (2020). Variation in COVID19 hospitalizations and deaths across New York City boroughs. Journal of the American Medical Association, 323(21), 21922195. https://doi.org/10.1001/jama.2020.7197

*Wright, L., Steptoe, A., \& Fancourt, D. (2021). Are adversities and worries during the COVID- 19 pandemic related to sleep quality? Longitudinal analyses of 46,000 UK adults. PLoS One, 16(3), Article e0248919. https://doi.org/10.1371/journal.pone.0248919

Wurman, T. V., Lee, T., Bateman, A., Fonagy, P., \& Nolte, T. (2020). Clinical management of common presentations of patients diagnosed with BPD during the COVID-19 pandemic: The contribution of the MBT framework. Counselling Psychology Quarterly, 1-27. https://doi.org/10.1080/09515070.2020.1814694

Yang, K., \& Victor, C. (2011). Age and loneliness in 25 European nations. Ageing and Society, 31(8), 1368-1388. https://doi.org/ $10.1017 / S 0144686 \times 1000139 X$ 


\section{History}

Received February 16, 2021

Revision received September 24, 2021

Accepted September 29, 2021

Published online January 5, 2022

\section{Acknowledgments}

We are thankful to Oliver Karrasch for his assistance in preparing the Supplement tables.

\section{Funding}

Open access publication enabled by University of Greifswald.

\section{ORCID}

Janine Wirkner

(D)https://orcid.org/0000-0003-0776-6140

\section{Janine Wirkner}

University of Greifswald

Institute of Psychology

Franz-Mehring-Straße 47

17489 Greifswald

Germany

janine.wirkner@uni-greifswald.de

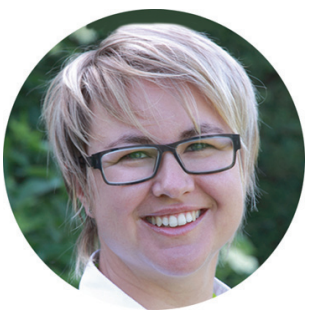

Janine Wirkner has a permanent position at the University of Greifswald and is head of research and education at the University Psychotherapy Outpatient Clinic in Greifswald, Germany. Her research focuses on stress, emotion processing and memory using ERPs, as well as on Dialectical-Behavior Therapy and mindfulness.

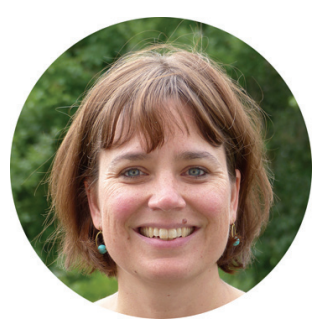

Hanna Christiansen is Professor of Clinical Child and Adolescent Psychology at Philipps University Marburg. Her research focuses on child and adolescent psychopathology, prevention and intervention and the transgenerational transmission of mental disorder.

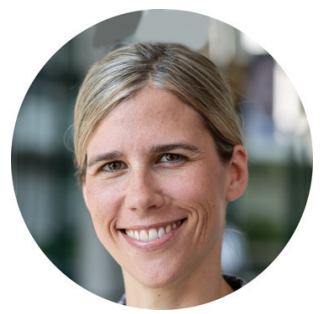

Christine Knaevelsrud is full professor for Clinical-Psychological Intervention at Freie Universität Berlin. She is head of the Center for Mental Health and Digital Science. Her research focuses on online-based psychological treatment approaches, trauma, and stress-related disorders and longterm bio-psycho-social effects of severe human rights violation.

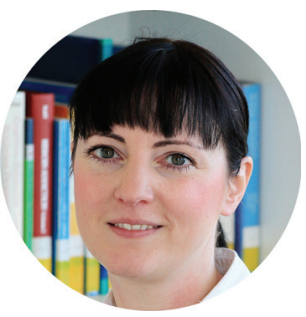

Ulrike Lüken is appointed full professor at Humboldt-Universität zu Berlin and leads a special outpatient unit for anxiety disorders. Her research focuses on optimizing CBT treatments based on an advanced understanding of the underlying neurobiological mechanisms and developing theranostic markers for treatment outcomes based on machine learning and artificial intelligence.

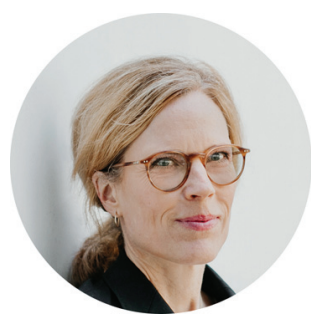

Susanne Wurm, PhD, Professor of Prevention Research and Social Medicine at the University Medicine Greifswald. Her research focuses on health and health behavior change in the middle- and later adulthood, subjective views on aging, adaptation after health events, and interventions to promote effective health behavior.

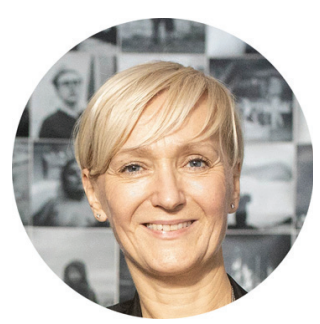

Silvia Schneider is Professor of Clinical Child and Adolescent Psychology at the Ruhr University Bochum (RUB) and Head of the RUB Mental Health Research and Treatment Center in Bochum, Germany. She conducts research on the etiology of emotional disorders in children and adolescents, clinical research in babies and toddlers, the familial transmission of anxiety disorders, and diagnostics of mental disorders.

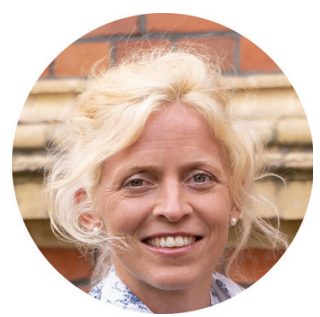

Eva-Lotta Brakemeier is Professor of Clinical Psychology and Psychotherapy at the University of Greifswald and Head of the University Psychotherapy Outpatient Clinic. Her research focuses on mechanism-based personalized psychotherapy, including clinical trials, practice-based monitoring and feedback, and basic research on mechanisms of change in psychotherapy. She actively fosters researcher-practitioner networks. 